\title{
INFLUÊNCIA DO TIPO DE ENZIMA NAS PROPRIEDADES FUNCIONAIS DE HIDROLISADOS OBTIDOS A PARTIR DE CONCENTRADO PROTEICO DE SORO DE LEITE
}

\section{J. S. TEIXEIRA ${ }^{1}$, T. L. D. SOARES ${ }^{1}$, M.S. SANTOS ${ }^{2}$, M.P. STEPHAN ${ }^{3}$, R. V. TONON ${ }^{3}$, A. I. S. BRÍGIDA ${ }^{3}$, C. MELLINGER-SILVA ${ }^{3}$}

\author{
${ }^{1}$ Centro Universitário Estadual da Zona Oeste \\ ${ }^{2}$ Universidade Federal Rural do Rio de Janeiro \\ ${ }^{3}$ Embrapa Agroindústria de Alimentos
}

E-mail para contato: ana.iraidy@embrapa.br; caroline.mellinger@embrapa.br

\begin{abstract}
RESUMO - A hidrólise enzimática parcial das proteínas do soro de leite pode incrementar suas propriedades funcionais. Dessa forma, testaram-se diferentes enzimas comerciais $\left(\right.$ Alcalase $^{\circledR}$, Neutrase ${ }^{\circledR}$, Novo Pro-D ${ }^{\circledR}$ e Protamex ${ }^{\circledR}$ ) a fim de verificar sua influência nas propriedades funcionais de hidrolisados obtidos a partir de concentrados proteicos de soro de leite. O maior grau de hidrólise (12\% após 2 horas de reação) foi observado tanto quando se utilizou Alcalase ${ }^{\circledR}$ quanto Novo Pro$\mathrm{D}^{\circledR}$. O uso da mistura Alcalase ${ }^{\circledR}$ mais Neutrase ${ }^{\circledR}$ mostrou-se eficiente se o objetivo é produzir um hidrolisado proteico parcial com alta capacidade emulsificante (80\%) e capacidade antioxidante $(297 \mu \mathrm{mol} \mathrm{TE} / \mathrm{g})$, sendo necessárias 1,5 horas de hidrólise. Contudo, se o objetivo é obter um hidrolisado com maior capacidade antioxidante $(378 \mu \mathrm{mol} \mathrm{TE} / \mathrm{g})$, porém também com capacidade emulsificante considerável $(70 \%)$, o uso apenas de Alcalase $^{\circledR}$ mostrou-se adequado, sendo economicamente mais rentável haja vista o curto tempo de reação necessário, menos de 5 minutos.
\end{abstract}

\section{INTRODUÇÃO}

As políticas para uma sociedade sustentável e ambientalmente amigável têm pontuado, além do uso de tecnologias de menor impacto ambiental, o uso de fontes renováveis e resíduos para obtenção de produtos de maior valor agregado (Angenent et al., 2004). Esses aspectos têm influenciado a obtenção de bioprodutos, produtos obtidos a partir de processos biotecnológicos, seja por extração, processos fermentativos ou reações enzimáticas. $\mathrm{O}$ desenvolvimento da biotecnologia no mundo vem trazendo diversas vantagens para a sociedade e para as indústrias, como a redução de impactos ambientais, a possibilidade do uso de matérias-primas renováveis, a obtenção de produtos ambientalmente corretos e a produção de rejeitos de baixa toxicidade. Os bioprodutos podem ser associados a diferentes segmentos industriais (químico orgânico, alimentício, farmacêutico, agrícola, etc.), além de apresentar valor comercial diferenciado. Os bioprodutos, além de serem obtidos a partir de processos mais limpos e, em alguns casos, de menor custo - haja vista a possibilidade de utilizar resíduos como matérias-primas para os mesmos, podem ser aplicados em processos de rota verde valorizando seu mercado e contribuindo para uma sociedade sustentável.

Dentre os bioprodutos aplicáveis na indústria de alimentos, têm-se os hidrolisados proteicos, os quais ganharam atenção, especialmente por apresentarem aspectos funcionais 
benéficos à saúde como atividade antioxidante, anti-hipertensiva, antimicrobiana e antianêmica. As fontes proteicas mais estudadas para obtenção de hidrolisado, especialmente devido à grande demanda do mercado, tem sido o soro de leite, coproduto da agroindústria do leite (He et al., 2013). O soro de leite é um coproduto de ampla utilidade na alimentação humana. Muitos estudos mostram que a hidrólise enzimática parcial das proteínas do soro de leite pode incrementar as propriedades nutricionais e funcionais deste coproduto, pois além de tornarem o material mais facilmente digerível, podem gerar peptídeos bioativos (Madureira et al., 2010) e favorecer ou manter as propriedades tecnológicas do material (Hernández-Ledesma et al., 2011). Assim, o objetivo deste trabalho foi avaliar a hidrólise das proteínas do soro de leite submetidas à ação de diferentes proteases verificando sua influência nas propriedades funcionais dos hidrolisados obtidos.

\section{MATERIAIS E MÉTODOS}

\subsection{Materiais}

As proteases comerciais Alcalase ${ }^{\circledR}$, Neutrase ${ }^{\circledR}$, Novo Pro- $\mathrm{D}^{\circledR}$ e Protamex $^{\circledR}$ foram gentilmente doadas pela Novozymes Latin America Ltda, Paraná, Brasil. O concentrado de soro de leite em pó (CWP 35) foi doado pela Alibra. Hexadecano e dodecil sulfato de sódio foram adquiridos da Sigma-Aldrich Chemical Co. Todos os outros reagentes utilizados foram de grau analítico e de diferentes marcas comerciais.

\subsection{Métodos}

Hidrólise enzimática do soro: O concentrado proteico de soro de leite (CWP 35) foi solubilizado em água ( $8 \%$ de proteína, p/p) e submetido a $55^{\circ} \mathrm{C}$. Antes da adição de enzima, o pH da solução foi ajustado para 8,5. Desta solução foi coletado o branco da amostra (Br). Em seguida, adicionou-se o volume de enzima adequado de forma a manter a relação enzima:substrato em $2,2 \%(\mathrm{p} / \mathrm{p})$ e esperou-se $1 \mathrm{~min}$ para a coleta do ponto 0 hora. As reações de hidrólise ocorreram sob agitação constante em reator encamisado. Os experimentos, bem como as análises dos pontos coletados, foram realizados em triplicata. A reação foi monitorada de acordo com o método $\mathrm{pH}$-stat, mantendo o pH constante através da adição contínua de $\mathrm{NaOH}$. O monitoramento da hidrólise enzimática das proteínas do soro de leite foi realizado para o acompanhamento do grau de hidrólise em função do tempo de processo. Para o cálculo do grau de hidrólise $(\mathrm{GH})$, a quantidade de base consumida foi anotado em função do tempo, variando em intervalos de 30 minutos inicialmente e aumentando gradativamente para intervalos de 60 em 60 minutos até que as variações do consumo da base fossem insignificantes.

O grau de hidrólise foi determinado pela Equação 1:

$$
G H(\%)=\frac{h}{h_{\text {total }}} \times 100=\frac{V_{n a O H} \times N_{b}}{M P \times \alpha \times h_{\text {total }}} \times 100
$$

onde,

$\mathrm{h}: \mathrm{n}^{\circ}$ de ligações peptídicas hidrolisadas 
$\mathrm{h}$ total: $\mathrm{n}^{\circ}$ de ligações peptídicas antes da reação

VnaOH: volume de base consumido

$\mathrm{N}_{\mathrm{b}}$ : normalidade da base adicionada durante a reação, de modo a manter o $\mathrm{pH}$ constante

MP: massa de proteína

$\alpha$ : grau de dissociação

Para obtenção do valor de alfa, que é a dissociação dos grupos $\alpha$-amino, utilizou-se a Equação 2:

$$
\alpha=\frac{1}{1+10^{p K-p H}}
$$

onde,

pH: é constante

pK: varia com a temperatura na qual a reação é conduzida.

O valor de pK pode ser estimado de acordo com a Equação 3:

$$
p K=7,8+\frac{298-T}{298 \times T} \times 2400
$$

onde,

\section{$\mathrm{T}$ : Temperatura $(\mathrm{K})$}

Também foi realizada amostragem do sistema reacional para determinação da capacidade emulsificante e da capacidade antioxidante. A reação foi interrompida nas alíquotas de amostragem por aquecimento destas a $85{ }^{\circ} \mathrm{C}$ por $15 \mathrm{~min}$. e, posterior, resfriamento em banho de gelo por $10 \mathrm{~min}$. Os resultados obtidos para cada enzima foram comparados a fim de se investigar o efeito individual da enzima utilizada nas condições de processo avaliadas.

Capacidade emulsificante: Esta foi avaliada através da determinação do índice de emulsificação da solução proteica em hexadecano P.A. Para tanto, $1 \mathrm{~mL}$ de amostra foi adicionada a $1 \mathrm{~mL}$ de hexadecano, em tubo de ensaio, e a mistura submetida a agitação em vortex, por 3 minutos. Ao fim da agitação, o sistema foi mantido sob repouso por 24 horas e, posteriormente, realizou-se a medida da altura total (At, $\mathrm{mm}$ ) da solução e da altura da fase emulsionada (Ae, mm). O índice de emulsificação (IE, \%) foi calculado de acordo com a Equação 4.

$$
\mathrm{IE}(\%)=\frac{\mathrm{Ae}}{\mathrm{At}} * 100
$$

Capacidade antioxidante: A capacidade antioxidante foi determinada pelo método espectrofotométrico baseado na descoloração do radical livre ABTS+ (ácido 2,2'-azino-bis-3etilbenzotiazolina-6-sulfônico sal diamônio 98\% pureza), de acordo com Re et al. (1999), 
utilizando tampão fosfato $(\mathrm{pH}=7,4)$ ao invés de etanol. Os resultados foram expressos como TEAC (Capacidade Antioxidante Equivalente ao Trolox) em $\mu \mathrm{mol} \mathrm{TE} / \mathrm{g}$ de proteína, porém, como houve variações entre os valores do branco, para melhor comparação, a capacidade antioxidante de cada hidrolisado foi normatizada a partir do seu branco equivalente.

Dosagem de proteínas: A quantificação de proteínas foi realizada pelo método de Bradford (1976).

\section{RESULTADOS}

A capacidade catalítica das proteases investigadas foi analisada através do grau de hidrólise das proteínas presentes no concentrado de soro de leite (Figura 1).

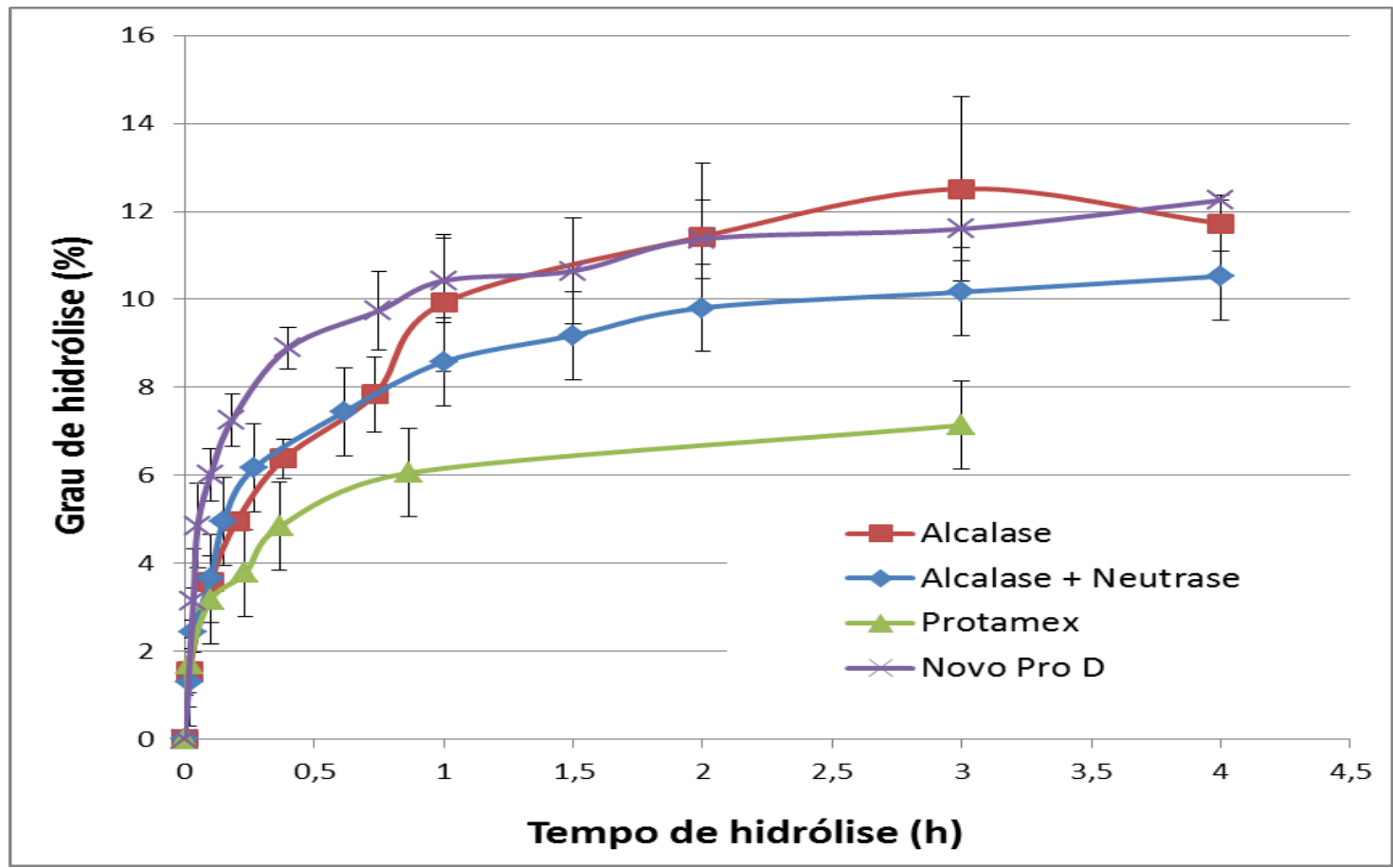

Figura 1 - Grau de hidrólise promovida na proteína do soro de leite em solução preparada a $8 \%$ a partir de $\mathrm{CPW} 35$, em reator encamisado a $55^{\circ} \mathrm{C}$, utilizando diferentes proteases.

Dentre as três enzimas avaliadas isoladamente, Protamex ${ }^{\circledR}$ apresentou menor grau de hidrólise, $7 \%$. Em condições e tempo de hidrólises diferentes, $5 \%$ de proteína inicial e $50^{\circ} \mathrm{C}$, Sindayikengera e Xia (2006) alcançaram até $20 \%$ de grau de hidrólise utilizando Protamex ${ }^{\circledR}$. Alcalase ${ }^{\circledR}$ e Novo Pro-D ${ }^{\circledR}$ apresentaram grau de hidrólise igual a $12 \%$ no equilíbrio, embora até 1 hora de reação a Novo Pro- $\mathrm{D}^{\circledR}$ tenha promovido uma velocidade de reação maior. A mistura de Alcalase ${ }^{\circledR}$ com Neutrase ${ }^{\circledR}$ também foi avaliada utilizando a proporção Alcalase ${ }^{\circledR}$ :Neutrase ${ }^{\circledR}$ de 5:3. Comparando a reação catalisada apenas com Alcalase ${ }^{\circledR}$ e a catalisada com a mistura Alcalase ${ }^{\circledR}$ e Neutrase ${ }^{\circledR}$, observou-se que não houve efeito positivo desta associação frente ao grau de hidrólise. Outras proteases promoveram grau de hidrólise maior que $40 \%$ em menos de 10 minutos de reação (Castro e Sato, 2013). 
Na Figura 2 tem-se a capacidade emulsificante dos hidrolisados obtidos a partir da catalise de proteínas de soro de leite utilizando diferentes proteases. A Novo Pro- $\mathrm{D}^{\circledR}$ foi a única enzima que produziu hidrolisados com menor capacidade emulsificante que a solução de proteína não hidrolisada. Isto pode ter ocorrido devido ao tipo de quebra promovido por esta protease, gerando frações peptídicas diferenciadas. Tal redução desta funcionalidade tecnológica implica numa limitação das aplicações deste hidrolisado, haja vista que reduz a estabilidade de emulsões elaboradas com esse hidrolisado, requerendo a adição de maior quantidade de estabilizantes e emulsificantes. Já os hidrolisados obtidos com Alcalase ${ }^{\circledR}$ apresentaram capacidade emulsificante igual à solução não hidrolisada, mostrando perda apenas com 5 horas de reação. Os hidrolisados obtidos com Protamex ${ }^{\circledR}$ e com a mistura Alcalase ${ }^{\circledR}$ e Neutrase ${ }^{\circledR}$ apresentaram aumento de $10 \%$ na capacidade emulsificante após 0,67 e 1,5 horas de reação, respectivamente. Banach et al. (2013) também observaram aumento na capacidade emulsificante em hidrolisados de proteína de leite utilizando tripsina, pepsina e chimiotripsina.

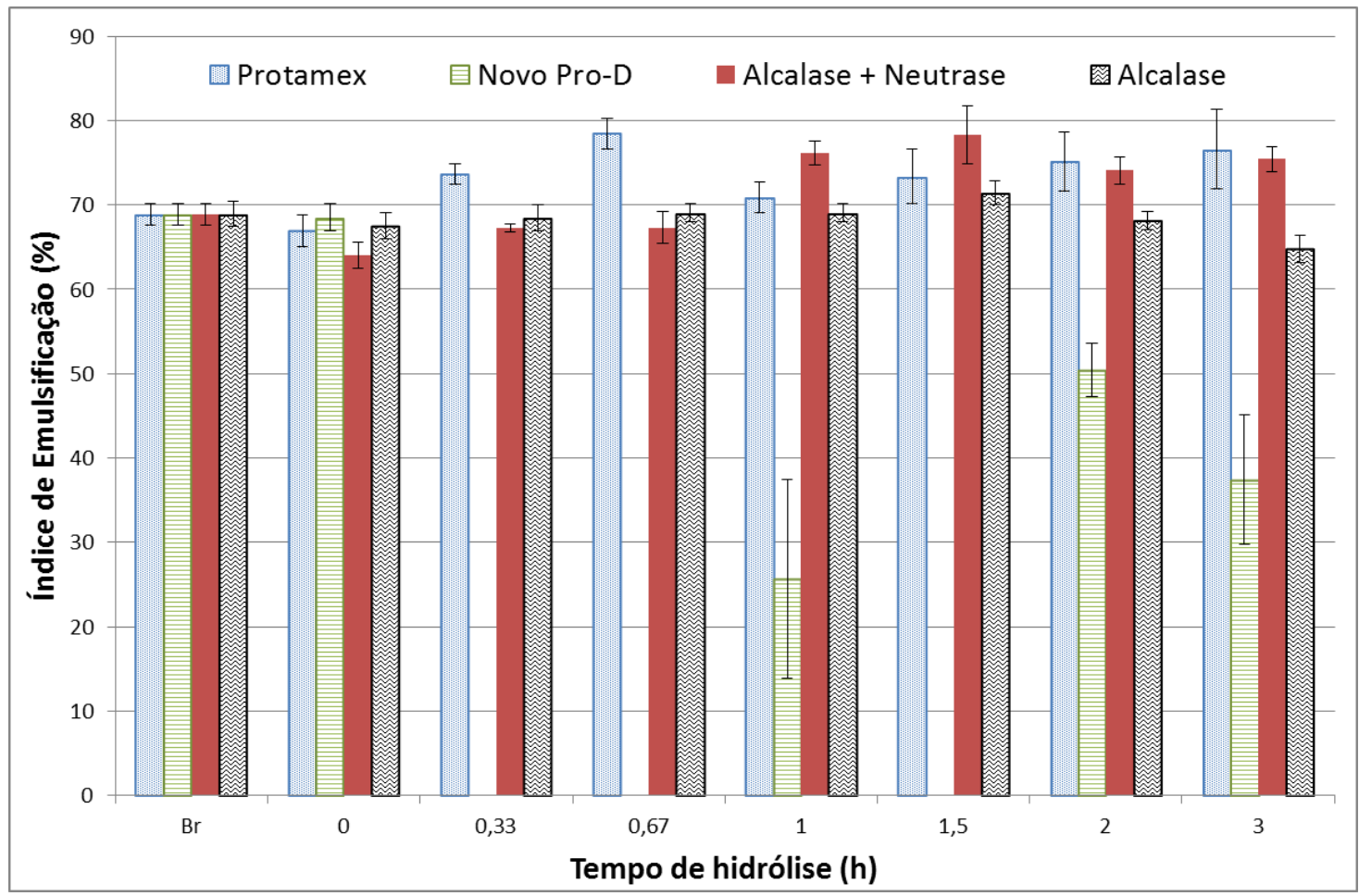

Figura 2 - Avaliação da capacidade emulsificante dos hidrolisados de proteínas do soro de leite em solução preparada a $8 \%$ a partir de CPW 35, obtidos em tempos reacionais distintos, em reator encamisado a $55^{\circ} \mathrm{C}$, utilizando diferentes proteases.

Como a Protamex ${ }^{\circledR}$ promoveu menor grau de hidrólise, apenas Alcalase ${ }^{\circledR}$ e Novo Pro-D ${ }^{\circledR}$ foram selecionadas para investigação da capacidade antioxidante dos hidrolisados (Figura 3). Os dados foram expressos em capacidade antioxidante normatizada, haja vista que a solução proteica não hidrolisada também apresentou capacidade antioxidante (TEAC média de $54 \pm 17$ $\mu \mathrm{mol} \mathrm{TE} / \mathrm{g}$ ), embora em menor valor frente aos hidrolisados. Este resultado corrobora com dados observados por Castro e Sato (2013), que também encontraram uma pequena atividade antioxidante na solução proteica inicial. 


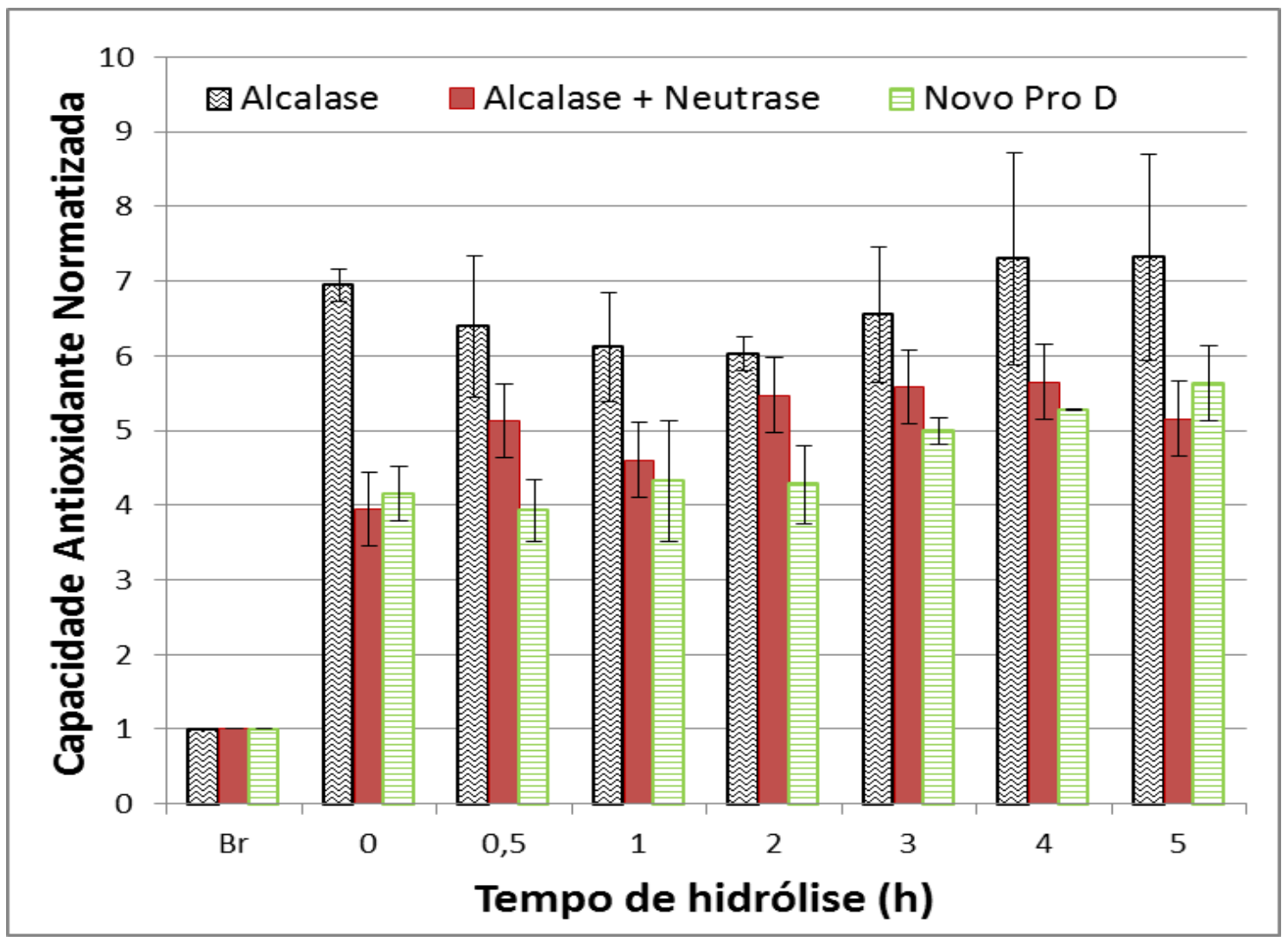

Figura 3 - Avaliação da capacidade antioxidante dos hidrolisados de proteínas do soro de leite em solução preparada a $8 \%$ a partir de CPW 35, obtidos em tempos reacionais distintos, em reator encamisado a $55^{\circ} \mathrm{C}$, utilizando diferentes proteases.

Já no primeiro minuto de reação (tempo $0 \mathrm{~h}$ ), com um valor médio de $3 \%$ de grau de hidrólise em todas as reações estudadas, observou-se um grande incremento na capacidade antioxidante da solução independente do tipo de protease estudada. Para Alcalase ${ }^{\circledR}$, o melhor tempo foi 0 hora (1min de reação), mostrando uma pequena queda nos tempos seguintes, embora em alguns casos os valores tenham sido estatisticamente iguais ao valor do tempo 0 hora. $\mathrm{O}$ valor da capacidade antioxidante encontrado nesta condição foi de $378 \mu \mathrm{mol} \mathrm{TE} / \mathrm{g}$, sendo este o hidrolisado mais ativo no presente estudo. Já a Novo Pro-D ${ }^{\circledR}$ promoveu um incremento maior apenas após 3 horas de hidrólise. A aplicação da mistura Alcalase ${ }^{\circledR}$ e Neutrase ${ }^{\circledR}$, embora tenha promovido incremento máximo em $0,5 \mathrm{~h}$ de reação, foi apenas 5 vezes enquanto que a reação catalisada apenas com Alcalase ${ }^{\circledR}$ foi 7 vezes maior que o valor da solução proteica não hidrolisada.

Em condições não otimizadas, Castro e Sato (2013) obtiveram hidrolisados com valor de capacidade antioxidante de até 9 vezes maior que a solução proteica não hidrolisada utilizando protease de Aspergillus oryzae. Contudo, quando estes realizaram otimização do processo, incremento de 23 vezes foi observado. 


\section{CONCLUSÃO}

O uso da mistura Alcalase ${ }^{\circledR}$ mais Neutrase ${ }^{\circledR}$ mostrou-se eficiente se o objetivo é produzir um hidrolisado proteico parcial com alta capacidade emulsificante (80\%) e capacidade antioxidante $(297 \mu \mathrm{mol} \mathrm{TE} / \mathrm{g})$, sendo necessárias 1,5 horas de hidrólise. Contudo, se o objetivo é obter um hidrolisado com maior capacidade antioxidante $(378 \mu \mathrm{mol} \mathrm{TE} / \mathrm{g})$, porém também com capacidade emulsificante considerável $(70 \%)$, o uso apenas de Alcalase ${ }^{\circledR}$ mostrou-se adequado, sendo economicamente mais rentável haja vista o curto tempo de reação necessário, menos de 5 minutos.

\section{AGRADECIMENTOS}

Agradecemos a FAPERJ pelo auxílio financeiro e ao CNPq pela bolsa concedida.

\section{REFERÊNCIAS}

ANGENENT, L.T.; KARIM, K.; AL-DAHHAN, M.H.; WRENN, B.A.; DOMÍGUEZESPINOSA, R. Production of bioenergy and biochemicals from industrial and agricultural wastewater. Trends Biotechnol., v. 22, p. 478-485, 2004.

BANACH, J.C.; LIN, Z.; LAMSAL, B.P. Enzymatic modification of milk protein concentrate and characterization of resulting functional properties. LWT - Food Sci. Technol., v. 54, p. 397403, 2013.

BRADFORD, M. M. A rapid and sensitive method for the quantification of microgram quantities of protein utilizing the principle of protein dye-binding. Anal. Biochem., v. 72, p. 248-254, 1976.

CASTRO, R. J. S.; SATO, H. H. Advantages of an acid protease from Aspergillus oryzae over commercial preparations for production of whey protein hydrolysates with antioxidant activities. Biocatal. Agric. Biotechnol., In Press, 2013.

HE, S.; FRANCO, C.; ZHANG, W. Functions, applications and production of protein hydrolysates from fish processing co-products (FPCP). Food Res. Int., v. 50, p. 289-297, 2013.

HERNÁNDEZ-LEDESMA, B.; CONTRERAS, M. M.; RECIO, I. Antihypertensive peptides: Production, bioavailability and incorporation into foods. Adv. Colloid Interfac., v. 165, p. 2335, 2011.

MADUREIRA, A. R.; TAVARES, T.; GOMES, A. M. P.; PINTADO, M. E.; MALCATA, F. $\mathrm{X}$. Invited review: physiological properties of bioactive peptides obtained from whey proteins. J. Dairy Sci., v. 93, p. 437-455, 2010.

RE, R.; PELLEGRINI, N.; PROTEGGENTE, A.; PANNALA, A.; YANG, M.; RICE-EVANS, C. Antioxidant activity applying an improved ABTS radical cation decolorization assay. Free Radic. Biol. Med., v.29, p. 1231-1237, 1999. 
SINDAYIKENGERA, S.; XIA, W.-S. Nutritional evaluation of caseins and whey proteins and their hydrolysates from Protamex. J. Zhejiang Univ. SCIENCE B, v. 7, p. 90-98, 2006. 